Orbis Tertius, vol. XXIII, nº 28, e092, diciembre 2018. ISSN 1851-7811

Universidad Nacional de La Plata

Facultad de Humanidades y Ciencias de la Educación

Centro de Estudios de Teoría y Crítica Literaria

\title{
Justo en el borde de la zona de certeza. Modos de la memoria en Los planetas de Sergio Chejfec
}

\section{Silvina Sánchez*}

* Universidad de Buenos Aires, Argentina.

Cita sugerida: Sánchez, S.(2018). Justo en el borde de la zona de certeza. Modos de la memoria en Los planetas de Sergio Chejfec. Orbis Tertius, 23(28), e092. https://doi.org/10.24215/18517811e092 


\title{
Justo en el borde de la zona de certeza. Modos de la memoria en Los planetas de Sergio Chejfec
}

\author{
por Silvina Sánchez \\ (Universidad Nacional de La Plata)
}

\begin{abstract}
Resumen:
Al revisar ciertas aproximaciones criticas a las narrativas sobre la última dictadura militar en Argentina, observamos que Los planetas de Sergio Cheifec se resiste a las interpretaciones disponibles, a los modos usuales de leer y a los intentos de sistematización. El artículo establece vinculos entre tales resistencias y la concepción de la memoria que trabaja la novela. La memoria se configura como un estado de paso que adopta formas imprecisas y transitorias, una experiencia que se sustrae de las organizaciones objetivas del espacio geométrico $y$ del tiempo cronológico. En este sentido, las temporalidades se acoplan con lo espacial: recordar significa reactualizar la estancia del cuerpo en la ciudad, volver a andar para hacer presente lo pasado.
\end{abstract}

Palabras clave: literatura argentina - dictadura - memoria - espacio - ciudad .

\section{ABstract:}

When analyzing certain critical approaches to narrations about the last military dictatorship in Argentina, we observe that Los planetas by Sergio Cheifec resists usual interpretations, expected reading modes and systematization efforts. This article establishes some links between such resistance and the idea of memory that is addressed in the novel. Memory is shaped as a passing state that adopts imprecise and transitory shapes; an experience that goes beyond objective organizations of the geometric space and the chronological time. In this sense, temporalities adapt to spaces: remembering means to update the presence of a body in the city, as well as walking around again in order to turn the past into present.

KEYWORDS: Argentine Literature - Argentine Dictatorship-memory - Space - City .

\section{LA FORMA DE UN SUEÑO}

La novela Los planetas de Sergio Chejfec, publicada en 1999 pero cuya escritura aparece fechada en "julio de 1994”, puede pensarse como parte de cierta constelación de relatos sobre la última dictadura militar en Argentina que comparten el mismo contexto de producción y circulación, así como también los circuitos de recepción y las operaciones de la crítica. ${ }^{1}$ Algunos trabajos, como "Políticas del decir y formas de la ficción. Novelas de la dictadura militar" de María Teresa Gramuglio - publicado en el número 74 de Punto de vista, 2002- y "La moral de la historia. Novelas argentinas sobre la dictadura (1995-2002)" de Miguel Dalmaroni -editado en el libro La palabra justa: Literatura, critica y memoria en la Argentina, 1960-2002, 2004-, se han vuelto referentes ineludibles fundamentalmente porque han ensayado periodizaciones donde las narrativas sobre la dictadura se distribuyen, organizan e interpretan. Gramuglio postula que la investigación de la CONADEP y el Juicio a las Juntas, con la publicación de Nunca más y del Diario del Juicio, introdujeron un "corte abrupto", que implicó un giro decisivo en el universo de los discursos, abriendo la vía a los "trabajos de la memoria", a una literatura testimonial, ampliada a otros soportes como cine y videos; además de modificar las condiciones discursivas para las novelas que volvían sobre la experiencia de la dictadura. Luego de hacer una mención a la narrativa sobre la guerra de Malvinas y a Calle de las Escuelas $N^{\circ} 13$ de Martín Prieto, Gramuglio se detiene en aquella dupla que pareciera destacarse en su análisis: Villa de Luis Gusmán y Dos veces junio de Martín Kohan, ambas emparentadas no solo por compartir algunos motivos sino porque en ellas "la ficción se topa con las hipótesis más polémicas que animan las mejores indagaciones sobre la memoria", tal como los postulados de Vezzetti sobre el consentimiento de la población con las políticas de exterminio dictatorial (2002: 14). Dalmaroni propone una hipótesis de periodización diferente, que permitiría "revisar" la formulada por Gramuglio: hacia mediados de los años noventa podría registrarse la emergencia de nuevas 
narrativas de la memoria del horror, distinguibles de una fase anterior, la signada por el informe Nunca más de la CONADEP y por el Juicio a las Juntas militares de 1985 (2004: 158). Para organizar el corpus coloca en el "centro" a Villa y Ni muerto has perdido tu nombre de Gusmán y Dos veces junio de Kohan, textos que le permiten conjeturar un "modelo provisorio de descripción" y pensar en una nueva novelística sobre la dictadura caracterizada principalmente por "abrir la posibilidad de narrar refiriendo por completo, y de modo directo, los sucesos y acciones más atroces e inenarrables" (2004: 159, cursivas en el original). Una vez delineado ese modelo de descripción, dice Dalmaroni, sería posible contrastarlo con otras novelas para establecer cuánto conviene diversificar y descronologizar, y aquí menciona a El secreto y las voces de Gamerro, Calle de las Escuelas $N^{\circ} 13$ de Prieto y Los planetas de Chejfec. En una nota al pie, agrega un dato que le parece "digno de mención": tres de las novelas del corpus que "mayores familiaridades presentan entre sí" (la segunda de Gusmán, la de Kohan y la de Gamerro) se publicaron en el 2002, año en que se editó el libro de Vezzetti que utiliza Gramuglio para fundamentar su periodización (2004: 159).

Si nos preguntamos por el lugar asignado a Los planetas en estas lecturas críticas, podemos ver que en el mapa construido por Gramuglio, donde señala las narrativas de la dictadura escritas en democracia a las que se les confiere un lugar relevante, Los planetas directamente no se menciona y en el mapa construido por Dalmaroni aparece pero, lejos de estar en el centro del corpus o presentar un carácter modélico, se encuentra entre las novelas que inducirían a repensar la hipótesis propuesta. Además Los planetas es aquella que menos relaciones presenta con las demás novelas consideradas, que en cambio se caracterizan por tener estrechos lazos de filiación, conexiones explícitas o "mayores familiaridades" entre sí. ${ }^{2}$ Por otro lado, si seguimos rastreando la recepción del texto de Chejfec, no podemos dejar de considerar la llamativa alusión que realiza Beatriz Sarlo en "La novela después de la historia. Sujetos y tecnologías" - publicado inicialmente en el número 86 de Punto de vista, 2006. Allí propone que, si la novela de los ochenta estaba obsesionada por el pasado de la dictadura y fue fundamentalmente "interpretativa", "el presente es el tiempo de la literatura que se está escribiendo hoy", constituyéndose como una línea visible la narrativa que se vuelve "etnográfica" (2007: 473). Cuando Sarlo realiza una salvedad respecto a su interpretación, dice que, a partir de las nuevas condiciones de producción -una saturación de discurso social sobre el pasado reciente-, se produce en la literatura un "desplazamiento hacia afuera de esa historia", aunque aclara: "salvo en aquellos escritores que descubren lo que todavía no ha sido dicho del modo en que ellos lo dicen (pienso en el extraordinario comienzo de Los planetas de Chejfec)" (2007: 472).

Con esta breve reseña pretendemos subrayar cómo Los planetas se resiste a ser capturada por las periodizaciones, agrupamientos y tendencias predominantes, es decir cómo se sustrae a las interpretaciones disponibles, a los modos usuales de leer y a las sistematizaciones formuladas por la crítica -ya sea por omisión en el mapa de lecturas (Gramuglio), por des-centralización y des-familiarización de los corpus propuestos (Dalmaroni), o por su carácter anómalo y excepcional (Sarlo). Refractaria a la explicación, parece disponer, más que la proyección de hipótesis interpretativas o modélicas, cierta zona de incertidumbre. En el presente artículo proponemos, en primer lugar, que pueden establecerse vinculaciones entre las disposiciones de lectura que la novela genera -con esto nos referimos a su condición refractaria o resistente- y los modos en que construye la memoria, es decir las formas y estrategias mediante las cuales reelabora el pasado traumático. Y, en segundo lugar, postulamos que el trabajo con la memoria se relaciona estrechamente con la dimensión espacial, aspecto crucial en la poética de Chejfec. ${ }^{3}$ De esta manera pretendemos explorar cómo se configura la memoria y qué relaciones pueden tramarse entre memoria, experiencia, tiempo y configuración de las espacialidades. Más que dar una respuesta a las cuestiones plateadas, pretendemos destacar la importancia de leer Los planetas entre las narrativas sobre la última dictadura y de preguntarnos por su condición resistente a los trazados de mapas, cronologías y tendencias.

Interrogarse por las configuraciones de la memoria en una escritura ficcional es quizás también un modo de pensar las relaciones de la literatura con la verdad y con el pensamiento. Blanchot, a partir de un análisis de 
la obra de Musil, dice que en una obra literaria se pueden expresar pensamientos tan complejos y de un modo tan abstracto como en una obra filosófica, pero con la condición de que aún no sean pensamientos. Y agrega:

El escritor tiene todos los derechos y puede atribuirse todos los modos de ser y de decir, salvo la tan frecuente palabra que aspira al sentido y a la verdad: lo que se dice en lo que dice aún no tiene sentido, aún no es verdad, aún no y nunca tanto; ese aún no es el esplendor presuntuoso que antaño se denominaba belleza (2005: 182).

En Los planetas el narrador denominado S cuenta la historia de su amigo M, secuestrado y desaparecido durante la última dictadura militar en Argentina. Es, más que la biografía de M, del que se dice más bien poco, la construcción de la experiencia de la pérdida, los modos en que $S$ ha sido afectado por la ausencia, lo que ha quedado en uno como recuerdo del otro. Quisiéramos partir de un momento de la novela para ensayar algunas hipótesis posibles sobre la construcción de la memoria: cuando el narrador lee el diario en un bar y encuentra la noticia de un estallido que asocia inmediatamente con la posible muerte del amigo. El narrador lee la crónica tres veces y luego queda aferrado al título que anticipaba "Explosión en P":

Sería exagerado decir que pensaba en algo, aunque tampoco es cierto que no pensaba en nada. Si existe una etapa previa a la conformación del pensamiento, un momento en que la conciencia intenta abrirse camino pero el mismo número de los detalles se lo impide, si existe esa etapa en la que los futuros pensamientos prefieren tomar la forma de un sueño, de un impulso sin voluntad, pasé por ella durante un tiempo demasiado largo... (2010:17).

Esa etapa previa a la conformación del pensamiento, especie de trance que experimenta el narrador cuando imagina la muerte del amigo, puede considerarse como síntesis del modo en que Los planetas configura la memoria-verdad, estado de paso o pasaje condensado en ese instante de alumbramiento del horror, que a la vez puede encontrarse diseminado en las distintas dimensiones y configuraciones del pasado, de la ausencia y de la pérdida que realiza la novela. Durante ese estado es imposible decir que el narrador pensaba en algo definitivo, asible en las gramáticas del pensamiento, pero tampoco puede decirse que tenía un blanco mental, pensamiento del afuera o de la nada. Es un estado de paso acechado por la proliferación de detalles que concentran la atención en lo mínimo, lo aleatorio y lo incidental en vez de dar lugar a la conciencia razonada, al establecimiento de lo global, lo general y lo representativo; estado en el que los pensamientos aún no son tales -cristalizados, organizados, comprobados-, sino que prefieren tomar la forma de un sueño, de un impulso sin voluntad. Así puede abordarse la poética de Chejfec desde los postulados de Blanchot: "lo que se dice en lo que dice aún no tiene sentido, aún no es verdad, aún no y nunca tanto" (2005: 182). La novela no aspira al sentido y a la verdad, pero de algún modo no deja nunca de tantearlos, como una proyección que adopta formas imprecisas y transitorias: recuerdos, fábulas, sueños, apariciones, imágenes, hipótesis. Ese ímpetu de búsqueda y sus formulaciones tentativas construyen un umbral poético que roza lo cierto, lo determinante y lo verdadero.

\section{UNA MEMORIA ESPACIALIZADA}

En La memoria, la historia, el olvido, Paul Ricoeur reflexiona sobre el vínculo entre la memoria y los lugares y discute ciertos postulados de la fenomenología del espacio. Establece un lazo primordial entre memoria y espacio: "las 'cosas' recordadas están intrínsecamente asociadas a lugares"; me acuerdo de haber vivido largo tiempo en tal o cual ciudad, de haber viajado a tal parte del mundo, de esos lugares de los que puedo decir "yo estuve allí" (2013: 62). De ahí que entiende el fenómeno de los lugares de memoria como indicadores que ofrecen un apoyo a la memoria que falla y participan en la lucha contra el olvido. Son inscripciones con carácter permanente -Ricoeur destaca su perdurabilidad-, lugares consagrados por la tradición y vinculados a la memoria colectiva.

Sin embargo, la configuración del vínculo tiempo-espacio en Chejfec escapa a estas condiciones: no podríamos hablar de recuerdos que se ligan a lugares, al modo de "me acuerdo de haber estado allí"; es decir del espacio tematizado. Tampoco se trata de lugares públicos de memoria. El estado de paso o pasaje al que 
aspira la novela como modo de memoria-verdad implica ciertas tensiones con las organizaciones objetivas y abstractas del espacio geométrico (euclidiano y cartesiano) y del tiempo cronológico y cronométrico, así como también con el emplazamiento de indicadores representativos de un colectivo identitario. Es un estado que permite ensayar figuraciones del espacio-tiempo más próximas a la memoria como experiencia, al modo en que han sido efectivamente vividos los acontecimientos, desmarcándose por momentos de las coordenadas del espacio geográfico y del sistema del calendario. En este sentido, es muy productivo instaurar un diálogo con otros planteos de Ricoeur, cuando revisa los aportes de la fenomenología de la datación y de la localización. Ricoeur recupera la idea de que la espacialidad vivida de algún modo se des-implica del espacio geométrico, pero advierte los riesgos de que esta des-implicación sea entendida como un a priori totalizante, absoluto. Entonces se pregunta: ¿puede mantenerse largo tiempo esta suspensión del espacio objetivado? (2013: 65).

En la novela de Chejfec, ese estado de paso significa, como ya dijimos, un acercamiento a la experiencia que se desajusta de las sistematizaciones del tiempo-espacio objetivas, en su sentido más conceptualizado. En principio es un relato de memoria donde la centralidad no la asume el tiempo sino el espacio. La coordenada temporal se desplaza de su eje hasta acoplarse al espacio, las temporalidades no solo se ven propiciadas y a la vez alteradas por el territorio sino que además son formas y manifestaciones de lo espacial. Esto se replica en el plano de las configuraciones y en el plano de la escritura a partir de la diseminación de trozos de tono ensayístico, imágenes y metáforas que participan de este desplazamiento. El ejemplo quizás más evidente sería el epígrafe, luego retomado en el capítulo 7 de la sección denominada "Final": "Del conjunto de países invisibles el presente es el más extenso”, pero también, entre muchos pasajes semejantes, aquél donde el espacio se define como "el más perdurable de los tiempos" (2010: 124). El espacio como experiencia viva asume distintas dimensiones que se yuxtaponen como capas o huellas de tiempo en la construcción de una memoria espacializada: el espacio urbano, el espacio móvil y a "gran escala" del caminante (2010: 172), el espacio de aprendizaje, el espacio como zona de violencia, el espacio como trabajo de memoria, el espacio astronómico, el espacio metafórico-poético, el espacio como escritura/tejido de zonas. Es evidente que se modifica la concepción prevaleciente, según Ricoeur, en la mayoría de los discursos sobre el espacio, donde el espacio vivido es sucesivamente abolido por el espacio geométrico. Sin embargo esta entronización del espacio como vivencia que realiza la novela tampoco significa una relación de ruptura o des-implicación total del espacio geométrico y topográfico. Es más bien la instauración de vínculos para nada unidireccionales sino multiformes, donde las marcaciones geométricas y topográficas se presentan especialmente como horizonte de configuración de la experiencia, al modo de roces y fricciones, alternancia de rupturas y suturas, según palabras de Ricoeur (2013: 196), y, podríamos agregar, de saturaciones, hiperlocalización y deslocalizaciones. Podríamos precisar entonces que en la novela el espacio objetivado no se corre o suspende para poner en primer plano el espacio vivido, sino que las vivencias se construyen en el entramado de acoplamientos y desacoplamientos entre los múltiples modos que asume el espacio, donde todas las configuraciones participan, desde la percepción abstracta hasta la materialidad más densa, desde lo público hasta lo privado, desde los mapas geográficos ofrecidos como guía del turista hasta los dibujos que imaginan las caminatas como si fueran constelaciones.

Por un lado, en Los planetas prevalece la ciudad de Buenos Aires, es en este aspecto donde se observa más claramente la hiperlocalización y el exceso de marcas territoriales: cada uno de los acontecimientos narrados, pero además cada pensamiento, recuerdo u ocurrencia del narrador, suceden en determinado barrio, calle, esquina, estación de ferrocarril. ${ }^{4}$ Hay un detallismo de la memoria que se obstina por recuperar y consignar la coordenada topográfica precisa en que lo anterior ha sucedido. Muy diferente es el trabajo con las coordenadas temporales: son pocas las fechas concretas que se mencionan en la novela -al interior solo el 21 de junio de 1973, al final la fecha de escritura-, y las restantes dataciones son más bien vagas - "una tarde de años atrás" (2010: 13), "años más tarde" (2010: 44)-, de modo que aquí también se evidencia el desplazamiento que postulamos anteriormente. Una datación aleatoria que se torna predominante y que 
asume un cariz más íntimo es una medición cronográfica (Ricoeur, 2013: 202), ligada a la experiencia de la pérdida, que convierte el secuestro en episodio fundacional a partir del cual se organizan y distribuyen los acontecimientos en el tiempo. Es decir, los sucesos se ubican en el pasado según la cantidad de años previos a la desaparición de M, como por ejemplo: "faltaban cuatro años para que M desapareciera" (2010: 164).

"La ciudad estaba atravesada por las líneas imaginarias de nuestros cuerpos en movimiento, [...] pero ellas no habrían existido sin Buenos Aires, como evidentemente tampoco nuestra relación" (2010: 176), dice el narrador. El espacio instaura un vínculo determinante con los personajes, posibilita su amistad y es el eje de sus acciones. Las principales actividades compartidas que se recuerdan son tránsitos por la ciudad, interminables caminatas conversadas. La amistad se define entonces como "territorial", es una forma del desplazamiento inmotivado. Así el cuerpo y sus modos de ser-estar en el espacio ocupan un lugar central: corporalidades en continuo movimiento, casi nunca fijas o quietas, que recorren no el centro de la ciudad sino fundamentalmente sus márgenes -zonas fronterizas, vías y puentes del ferrocarril, mezcla de barrio y suburbio, el Conurbano. Cuerpos que se mueven como si el tránsito estimulara el relato de anécdotas y fábulas, el contrapunto de argumentos en tono reflexivo, es decir cuerpos que devienen palabra y escucha. Pero además como si el tránsito fuera la ocasión de la aventura, movimiento bajo un impulso de búsquedas y encuentros: el recorrido de M y sus amigos por las vías "buscando piedras de formas extraordinarias" (2010: 28), la búsqueda del auto robado del padre de $\mathrm{M}$, el hallazgo del ojo, así como también los increíbles encuentros de $\mathrm{M}$ y $\mathrm{S}$ en la ciudad; el encuentro con la madre de M, el encuentro con Sito. Estas búsquedas y hallazgos espaciales son la materia narrativa de que se compone la novela. Es también el desplazamiento urbano lo que posibilita que el espacio se convierta en zona de formación: "al ritmo de esos pasos y palabras M y el otro se conformaron: juntos aprendieron a pensar, a conversar incluso; y podría agregarse: a caminar en su más pleno sentido" (2010: 127). Esa zona de aprendizaje se vuelve suplemento que remeda la ausencia de adultos formadores, el movimiento no solo es proyectivo sino que además des-anda los aprendizajes previos para transformarlos: el caminar como hábito naturalizado y compulsivo se convierte en ritual del paseante, donde todo adquiere densidad y espesor, caminar como devenir cuerpo-percepción-búsqueda-pensamientopalabra.

Los cuerpos y su espaciamiento reaparecen en otros momentos de la novela pero vinculados a la violencia política. Los efectos del horror de la dictadura se manifiestan como un emplazamiento invasivo del cuerpo en el espacio común: cadáveres, pero también cuerpos trozados y desmembrados, restos de cuerpos regados en el paisaje. ${ }^{5}$ Además la ciudad se ve invadida no solo por los cuerpos masacrados, que primero aparecen en zanjas y baldíos y luego adoptan la forma de "cadáveres ambiguamente anónimos" (2010: 215), sino también por su presencia espectral o fantasmática: "Buenos Aires se llenaba de muertos" (2010: 221), "Parecía haber más muertos que vivos y más cadáveres que muertos” (2010: 215). Varias veces se comenta que el secuestro de M tuvo lugar en la casa de un amigo, al que supuestamente habría ido a visitar: este trastrocamiento de lo propio, lo conocido por todos (la casa-la cuadra-el barrio) hacia lo extraño e indeterminado vuelve inasimilable el acontecimiento para la percepción de sus allegados. El narrador interpreta este hecho como una "falta de concurso entre suceso y geografía" (2010: 138), es decir, reconoce un hecho traumático al que no se le puede asignar lugar, cuestión que aparece enfatizada por la condición de desaparecido y la carencia de sepultura: tampoco hay lugar donde localizar su cuerpo, ni sitio donde tramitar su muerte. Todo esto incide fuertemente en la experiencia de la pérdida, tornándola inabarcable.

De esta manera volver a andar el espacio es intentar hacer presente lo anterior. Si para Ricoeur el esfuerzo de memoria es en gran parte esfuerzo de datación, de responder a la pregunta ¿cuándo?, aquí el tiempo se desliga de la ubicación en un sistema cronológico progresivo y lineal porque la pérdida lo ha trastornado de diversos modos. Es un tiempo anómalo, dilatado, de una "duración intolerable" (2010: 36), donde se ha alterado la sucesión y se aplaza sin término la conclusividad, de modo tal que los parámetros de datación friccionan con la temporalidad tal como es vivida: "por semanas los días no pasaron" (2010:21). El esfuerzo de memoria no es temporal sino espacial, pero esta espacialidad no se constituye según la noción dominante de 
inscripción desarrollada por Ricoeur - marcas adoptadas como enlaces para el trabajo de memoria. El espacio no es un indicador o apoyo exterior que activa el recuerdo, es parte constituyente de la experiencia, el trabajo de memoria significa reactualizar la estancia del cuerpo en el espacio como un modo de materializar lo ausente, recuperar lo que se ha perdido en términos de vivencia, lo que además significa una actualización del impulso de movimiento y de búsqueda. El narrador realiza periódicas visitas al barrio de $\mathrm{M}$, vuelve a los alrededores de lugares frecuentados, a la biblioteca a la que han ido juntos. Sin embargo, después de recorrer la proximidad de la casa de M regresaba todos los días "con las manos vacías", el espacio se ha vuelto "mudo", no dice ni muestra nada (2010: 124). El resultado es una y otra vez trunco y fallido, siempre la misma decepción, porque lo que se ha ido a buscar a otro lugar-tiempo ya no está allí, porque el espacio "una vez que faltó M acabó borrado" (2010: 124). En este sentido, podríamos decir que la ciudad ha cambiado a partir de la ausencia. La pérdida desata un proceso de disolución, dando lugar a la extraña licuación de lo sólido, a la dispersión de lo permanente y duradero: "las cosas concretas de la ciudad, levantadas con sustancias que se endurecen al fraguar y resisten el tiempo, ahora se disolvían en un núcleo de desorden” (2010: 21). La disolución del espacio personal contrasta con la permanencia del espacio social y público, con la continua reproducción de lo mismo, inalterado e indiferente ante el horror y la falta: los mismos colectivos siguiendo una y otra vez el mismo recorrido, la misma gente que seguía habitando la ciudad y "hablando como si nada hubiera pasado" (2010: 22). ${ }^{6}$

En cierta oportunidad M le comenta: "A veces pienso que andamos por la ciudad como planetas, siguiendo una trayectoria individual y con una misma posición relativa navegamos según dibujos uniformes” (2010: 131). Aunque el narrador lo corrige diciendo que los planetas no se mueven así, en todo caso serían las estrellas o los astros los elementos más indicados para establecer esta analogía, $\mathrm{M}$ no lo escucha y finalmente termina imponiéndose aquella figuración: "el movimiento aparente de aquello que está en el cielo [...] se convirtió, por obra de la casualidad, en clave y emblema de nuestro vínculo” (2010: 131). Los lazos entre los diagramas del paseo y las órbitas de los planetas, entre movimiento urbano y astronómico, nada tienen de pertinencia científica, se permiten ser incorrectos porque funcionan como correspondencia no racional sino poética. La lógica de las constelaciones agrega a los recorridos de los personajes no solo la posibilidad de proyectarlos en un diagrama que tendría ciertas líneas y tendencias permanentes sino que además, y fundamentalmente, les otorgaría una influencia recíproca. Es decir los itinerarios individuales de los amigos responderían a una organización solidaria, pautada por principios de equilibrio y compensación, susceptible de alejamientos, vacíos y distancias así como también de cruces y aproximaciones sorprendentes, tales como los dos encuentros callejeros, largo tiempo después de haberse despedido y tomado direcciones opuestas. Este andar constelado se vuelve potencia intangible que los comunica y conecta, implicando una concepción de los cuerpos definidos por sus consecuencias o señales más que por su masa o materialidad (2010: 130-131), de ahí que el narrador pueda recibir impresiones parciales del recorrido de $\mathrm{M}$ a pesar de la lejanía; que se pregunte si, luego de la muerte del amigo, puede seguir actuando este lazo invisible y muchas veces intuya sus efectos en los acontecimientos del presente, como por ejemplo cuando siente la intervención de $\mathrm{M}$ en el encuentro con Sito. Entonces el espacio urbano admite mapas simultáneos, superpuestos como capas geológicas, aunque no homologables: al dibujo de las constelaciones, líneas transparentes que conectan a los cuerpos de los amigos en movimiento, se agrega el plano en forma de libro, donde el padre de $\mathrm{M}$ organiza los recorridos por el Conurbano y donde los amigos escogen los sitios que desean conocer, y a la vez el mapa topográfico -que podría rearmarse- de los barrios y zonas de Buenos Aires recorridos efectivamente por los personajes en las caminatas que se narran en la novela. Los trazos de estos dibujos se desmarcan de los mapas de la organización arquitectónica y urbanística de la ciudad. Si los mapas ofician como guía del ciudadano o del turista que resalta ciertas zonas, patrimonios, monumentos como aquello que merece ser visto y visitado, al tiempo que omite e invisibiliza tantas otras, los diagramas de las constelaciones-caminatas de los amigos funcionan como deslocalización de esa tipología urbana; su vivencia del espacio despliega la posibilidad de usos y trayectos no programados ni divulgados. 
De este modo, el espacio astronómico - planetas, astros, estrellas - funciona como constelación metafórica que se disemina propiciando sentidos para imaginar no solo la trayectoria urbana de los protagonistas sino además aspectos como la identidad y la alteridad. Esta densidad metafórica vuelve a la escritura espacio de exploración poética. El espaciamiento poético se entreteje, en la dinámica de roces y fricciones que anunciamos al comienzo, con los otros modos de escritura que se despliegan: una zona de ensayo donde proliferan las fórmulas argumentativas, volviéndola una novela hiperescrita que refiere continuamente a lo que se escribió antes o a lo que vendrá después, o que refuerza el motivo de las operaciones realizadas. ${ }^{7}$ Pero además hay una zona de fabulación donde se recupera la narración oral como don, la capacidad de contar historias, anécdotas, sueños, obras de arte, la disposición a la escucha, la posibilidad de cazar un germen de relato al pasar por las mesas de un bar dispuestas en la vereda, al cruzar una calle o esperar en una esquina. Entonces el espacio de la escritura se construye como fricción de estas zonas-tonos: narración, argumentación, poética coexisten entretejiéndose. Y es quizás ese tramado el que les hace compartir cierta propulsión a multiplicar los sentidos sin asir a ninguno como único o privilegiado, a deslizarse tangencialmente por los bordes, al límite de la zona de certeza.

\section{EL BORDE}

En una de las tantas descripciones que el narrador realiza de su amigo comenta que "sus creencias fueron siempre hipotéticas, se detenían justo en el borde de la zona de certeza” (2010: 73). La idea de borde se liga al estado de paso que comentamos al principio: un pensamiento conjetural que circula los bordes pero se detiene al límite de la zona de certeza y efectuación. En esta dirección, podríamos postular la idea de un saber-hacer del borde como operación gnoseológica y también como praxis del narrador. En primer lugar, esto puede verse en lo que anticipamos: la tendencia a desarticular la fijación del sentido. Por ejemplo, en el caso de la dimensión narrativa, ante la proliferación de fábulas e historias, tanto $\mathrm{M}$ como el narrador arguyen distintas lecturas, discuten sentidos, pero este proceso se vuelve sobre-interpretación generando como efecto la dislocación del mensaje, de la moraleja y del funcionamiento alegórico. También en otro plano de la narración, la construcción biográfica del amigo, sucede algo similar, todo lo que se relata de su vida aparece como disposición de hipótesis: el secuestro se propone como dependiente del azar y la militancia aparece negada pero no se elimina la posibilidad de que M haya tenido otra vida desconocida por sus amigos, el narrador asocia una explosión como episodio final pero aclara que no tiene forma de comprobar la presencia de $\mathrm{M}$ allí. Los acontecimientos, más que hechos efectivamente confirmados, asumen la forma de conjeturas, susceptibles de ser ciertas, pero también de falsarse y quedar descartadas.

Hacia el final de la novela, el narrador cuenta su intento de cambiarse el nombre por el de M, especie de continuidad del legado, modo de restablecer el lazo de compenetración que habían alcanzado aunque sea de forma verbal-figurativa (2010: 257). Cuando va al registro civil le informan que la única posibilidad es que demuestre, a través de pruebas de carácter documental y público, el uso arraigado del nuevo nombre como propio. Entonces, como un modo de conseguir datos, instaura una relación íntima con la empleada del registro civil, quien le da la idea de publicar una novela con el nuevo nombre y luego presentar esta prueba como causal. Sin embargo, cuando tiene a su alcance la posibilidad concreta y efectiva de llevar adelante esta operación, cuando están dispuestas las estrategias para poder consumar la acción, decide no concretar el cambio de nombre. Quizás ese saber-hacer del borde convierte a la praxis en proyección frustrada, un deseo de hacer que circula en los márgenes de la acción sin pasar a la realización efectiva. Algo similar puede postularse en relación al olvido. Si tomamos como referencia el capítulo sobre los usos del olvido de La memoria, la historia, el olvido, podemos observar que el narrador se ve afectado por varias de las modalidades que describe Ricoeur: el olvido como huida de aquello de lo que no queremos hablar-por ejemplo cuando se recrimina que en toda la larga conversación con Sito no fueron capaces de mencionar o evocar cabalmente a $\mathrm{M}-$, o el olvido como erosión de las huellas, los rastros y las señales que remiten al amigo. Sin embargo, se ve imposibilitado de 
experimentar lo que Ricoeur conceptualiza como un "uso ético". En este caso el olvido cumpliría una función liberadora: aligerar la carga del pasado permitiría que entre en escena una "verdadera ética del olvido", capaz de contraer nuevos compromisos, de hacer promesas (Ricoeur, 2006: 75). El narrador asume el peso de la deuda y es proyectado-hablado por ella. Decide ser escritor porque eso hubiera sido $\mathrm{M}$ si viviera, como un gesto de restitución, y escribe su relato dictado por la memoria de M, bajo la estela de su figura venerada, omnipresente hasta la idealización, evitando decir o hacer cualquier cosa que pueda opacar su recuerdo o traicionarlo. En este sentido, no logra lo que Ricoeur propone respecto a la herencia: proseguir en el corazón mismo de la deuda, pero realizando el sutil trabajo de desatar y de atar (2013: 643). El narrador pareciera no poder liberarse de la falta, no logra proyectar nada - una relación, un deseo, una palabra- que se desligue de la repetición de la memoria y auspicie el porvenir. Reside en un "presente plano", duración prolongada de la pérdida: "de este tiempo liso y trasparente me ha resultado imposible liberarme; allí divago, transcurro, recuerdo y adivino a M" (2010: 277). Su ejercicio es reactualizar lo anterior para evitar que muera en él, es volver a soñar la amistad con $\mathrm{M}$ para revivir, en ese episodio onírico y luego en los destellos que el sueño irradia al despertar, su intimidad.

Hay un momento de la novela donde Mle pregunta a su amigo: “¿Hay un lugar donde los recorridos hablen por nosotros sin necesitar de nuestro énfasis? El otro no respondió. Si existe, no sabemos dónde está; y si no existiera deberíamos inventarlo." (2010: 128). Las huellas faltan, se pierden, se difuminan, el espacio y las marcas que dejaron sus pasos se han ido borrando; tal como sugiere $\mathrm{M}$, probablemente deban inventar ese lugar. La literatura de Chejfec se crea como lugar de memoria, estado de pasaje inconcluso que admite todos los espacios -geométrico, topográfico, astronómico, urbano, vivencial-, todas las metáforas poéticas, todos los sentidos conjeturales, todos los argumentos y a la vez ninguno, porque resiste cualquier forma de fijeza, porque allí los recorridos hablan por sí solos y sin énfasis, porque su modo de captar la verdad es en pleno deslizamiento, al paso.

\section{BIBLIOGRAFÍA}

Alcívar Bellolio, Daniela (2012). Una mínima inclinación. Imagen de autor en los ensayos de Sergio Chejfec. Iberoamericana, XII(48), 61-78.

Berg, Edgardo (2012). Sergio Chejfec: un estilo vagabundo y fuera de casa. En M. Bueno (comp.), La novela argentina: experiencia y tradición (pp. 119-139). Buenos Aires, Corregidor.

Blanchot, Maurice (2005). El libro por venir. Madrid: Trotta.

Chejfec, Sergio (2010). Los planetas. Buenos Aires: Alfaguara.

Dalmaroni, Miguel (2004). La moral de la historia. Novelas argentinas sobre la dictadura (1995-2002). En M. Dalmaroni, La palabra justa: Literatura, crítica y memoria en la Argentina, 1960-2002 (pp. 155-174). Mar del Plata-Santiago de Chile: Melusina.

Gramuglio, María Teresa (2002). Políticas del decir y formas de la ficción. Novelas de la dictadura militar. Punto de vista, 74, 9-14.

Quintana, Isabel (2010). Los planetas de Sergio Chejfec: vacilaciones de la memoria. En R. Carbone y A. Ojeda (comps.), Literatura argentina siglo XX, de Alfonsin al menemato (1983-2001) (pp. 165-173). Buenos Aires: Paradiso.

Ricoeur, Paul (2006). El olvido en el horizonte de la prescripción. En P. Ricoeur y otros, ¿Por qué recordar? (pp. 73-76). Buenos Aires: Granica.

Ricoeur, Paul (2013). La memoria, la historia, el olvido. Buenos Aires: Fondo de Cultura Económica.

Sarlo, Beatriz (2007). La novela después de la historia. Sujetos y tecnologías. En B. Sarlo, Escritos sobre literatura argentina (pp. 471-482). Buenos Aires: Siglo XXI. 


\section{Notas}

1 Sergio Chejfec nació en Buenos Aires en 1956. Ha publicado las novelas Lenta biografia (1990), Moral (1990), El aire (1992), Cinco (1996), El llamado de la especie (1997), Los planetas (1999), Boca de lobo (2000), Los incompletos (2004), Baroni: un viaje (2007), Mis dos mundos (2008) y La experiencia dramática (2012). También ha publicado dos libros de poemas: Tres poemas y una merced (2002) y Gallos y huesos (2003), y una compilación de cuentos titulada Modo linterna (2013). Además, escribe ensayos y artículos sobre crítica literaria y cultural, algunos de ellos compilados en los libros: El punto vacilante. Literatura, ideas y mundo privado (2005), Sobre Giannuzzi (2010) y Últimas noticias de la escritura (2015).

2 Los lazos de filiación y las conexiones explícitas se refieren a las relaciones que mantiene Dos veces junio respecto a su antecesora Villa, señaladas en estos términos por Gramuglio (2012: 12) y Dalmaroni (2004: 163). Respecto al capítulo del libro de Dalmaroni, también podríamos agregar que Los planetas, junto con Calle de las Escuelas $N^{\circ} 13$ de Prieto, serían las únicas dos de todas las novelas mencionadas a las que no se les dedica un momento de análisis más particularizado.

3 La relevancia del espacio en la poética de Chejfec y en particular en Los planetas ha sido señalada con insistencia por la crítica, véase por ejemplo: "Sergio Chejfec: un estilo vagabundo y fuera de casa" de Edgardo Berg (2012), "Los planetas de Sergio Chejfec: vacilaciones de la memoria” de Isabel Quintana (2010), "Una mínima inclinación. Imagen de autor en los ensayos de Sergio Chejfec" de Daniela Alcívar Bellolio (2012), entre muchos otros trabajos. Otras cuestiones importantes en el análisis de Los planetas, que no podremos desarrollar aquí pero que no queremos dejar de mencionar, son: el nombre y la fragilidad de la identidad, la relación entre memoria e imagen, a partir del tema de la fotografía; la relación entre memoria y narración -cómo pensar la falta de anécdota (resaltada mayoritariamente por la crítica) frente a la proliferación de relatos y fábulas-, los vínculos entre la Historia política y las historias mínimas.

4 Como por ejemplo: “Me preguntaba entonces, sobre la calle Rodríguez Peña” (2010:271), “A media cuadra de San Juan pensé” (2010: 156).

5 Ejemplo de esto es la crónica de la escena de la explosión, donde los cuerpos, impactados por el estallido, "deshechos después de haber sufrido, separados en trozos", aparecen esparcidos en una extensa superficie de campo abierto, a la intemperie (2010: 14).

6 Por otro lado, puede leerse también en la novela cómo el espacio está cambiando por el impacto de las aceleradas transformaciones de los años noventa: se multiplican las fronteras al ritmo del acrecentamiento de las distancias económicas y sociales, la ciudad se amuralla, se fractura, se guetifica, bajo lógicas de mercantilización y privatización en auge. Volver a andar los bordes, volver a un uso público del espacio es aferrarse a esa ciudad anterior, abierta, amplia, en plena desaparición, es rehuir las lógicas auspiciadas como novedad alentadora por el neoliberalismo más radical y virulento. "Esa ciudad antigua sigue siendo nuestro umbral" (2010: 21), dice el narrador.

7 Ejemplos de esta hiperescritura son la aparición de indicaciones como: "Ahora voy a describir aquel extrañísimo suceso." (2010: 129), "Voy a demostrarlo con un ejemplo." (2010: 149), "Sin embargo voy a dar un ejemplo profundo." (2010: 221); y de fórmulas que funcionan como referencias al interior del texto: “Antes me referí a” (2010: 33), “Antes dije que” (2010: 34), “como recién dije” (2010: 149). 